\title{
FENOMENA PROSTITUSI ONLINE DI KOTA YOGYAKARTA DALAM PERSFEKTIF NILAI KEMANUSIAAN YANG ADIL DAN BERADAB
}

\author{
T Heru Nurgiansah \\ Universitas PGRI Yogyakarta, Yogyakarta, Indonesia \\ nurgiansah@upy.ac.id
}

\begin{abstract}
In the millennial era as it is now the utilization or use of social media seems to be a primary necessity. It is undeniable that the Internet network can resurface the issues between the right and the vanity. Many internet users are peddling their wares online such as accessories, clothing, and food. But the fact on the field is also a lot that uses social media to do activities that violate the norm, one of which is online prostitution. Indonesia with its Pancasila ideology wants all citizens to uphold the values contained in Pancasila. Please second aims to humanize human beings according to the dignity and the dignity to be a civilized person. The perpetrators of prostitution pretext that their activities are based on the injustices in life. Even they took refuge in human rights in the peddling of him. The study used case studies with qualitative methods to be able to uncover the veil of increasingly booming prostitution with various breakthroughs and find its way out so that the perpetrators aware that their activities are contrary to the fair and civilized value of humanity. One solution is to include the perpetrators of prostitution into religious schools.
\end{abstract}

Keywords: prostitution, Pancasila.

\begin{abstract}
Abstrak
Di era milenial seperti sekarang ini pemanfaatan atau penggunaan media sosial seolah menjadi kebutuhan primer. Tidak bisa dipungkiri bahwa jaringan internet mampu membiaskan persoalan antara yang hak dan yang batil. Banyak pengguna internet yang menjajakan barang dagangannya secara online seperti asesoris, pakaian, dan makanan. Akan tetapi fakta di lapangan banyak juga yang menggunakan media sosial untuk melakukan kegiatan yang melanggar norma, salah satunya adalah prostitusi online. Indonesia dengan ideologi pancasila-nya menginginkan semua warga negara menjunjung tinggi nilai-nilai yang terkandung dalam pancasila. Sila kedua bertujuan untuk memanusiakan manusia sesuai harkat dan martabatnya agar menjadi pribadi yang beradab. Para pelaku prostitusi berdalih bahwa kegiatan mereka didasari atas ketidakadilan dalam hidup. Bahkan mereka berlindung kepada hak asasi manusia di dalam menjajakan dirinya. Penelitian ini menggunakan studi kasus dengan metode kualitatif agar mampu mengungkap tabir permasalahan prostitusi yang semakin menggeliat dengan berbagai terobosan baru dan mencari jalan keluarnya agar para pelaku prostitusi sadar bahwa kegiatan mereka bertentangan dengan nilai kemanusian yang adil dan beradab. Salah satu solusinya adalah memasukan para pelaku prostitusi ke dalam pesantren.
\end{abstract}

Kata kunci: prostitusi, Pancasila

Sejarah Artikel: Diterima 31 Juli 2020 | Direvisi hingga 09 September 2020 Diterima 11 September 2020 | Publikasikan 21 September 2020 


\section{PENDAHULUAN}

Salah satu penyakit masyarakat yang susah untuk diatasi adalah prostitusi. Jika dulu kegiatan ini dilakukan secara sembunyi-sembunyi maka pada saat ini pelaku prostitusi semakin berani menampakkan hidungnya bahkan sampai dengan lokasi dan tarifnya pun bisa diakses oleh siapapun, kapanpun dan dimanapun. Hal ini membuktikan bahwa ada pergeseran baik dari cara penjajakannya maupun dari segi motif. Dahulu perempuan menjadi Pekerja Seks Komersial dilandasi oleh masalah ekonomi, namun sekarang motifnya berubah karena alasan hedonisme. Ekspektasi yang tidak sesuai dengan realita dilapangan, rasa iri tidak bisa seperti kehidupan orang lain, dan kehidupan glamor merupakan satu diantara puluhan alasan orang menjadi Pekerja Seks Komersial. Dan mirisnya lagi para pekerja seks ini masih berusia muda.

Penyebab terjadinya praktik prostitusi di kalangan generasi muda pada umumnya karena adanya faktor ekonomi (Prayoga SM, 2019). Faktor ekonomi di pengaruhi oleh penghasilan atau kebutuhan seseorang (Marcius \& Simatupang, 2018). Banyak faktor yang menjadi penyebab perempuan terjun ke dalam kegiatan prositusi seperti taraf prekonomian yang rendah mengakibatkan pemenuhan kebutuhan hidup tidak dapat terpenuhi, sikap hedonisme yang membuat seseorang kalap tanpa pikir panjang ingin terlihat hidup mewah dan glamor tanpa memikirkan apakah hasil pendapatannya diperoleh dengan cara yang halal atau tidak, ketidakharmonisan dalam berumah tangga menjadikan pasangan suami istri mencari pelarian untuk menyalurkan hasratnya, dan meningkatnya peredaran video porno yang diperjualbelikan di pasaran atau yang di akses di website tertentu. Prostitusi sendiri tidak lepas dari kebutuhan ekonomi, kebutuhan makan, perumahan dan kebutuhan lainnya harus dipenuhi. Bukan berarti dengan keterbatasan lapangan pekerjaan bagi perempuan akan menghentikan kebutuhan mereka sebagai salah satu pilar ekonomi keluarga. Salah satu pilihan mudah bagi pekerjaan perempuan dengan keterampilan dan pendidikan rendah dengan harapan mendapat kehidupan yang layak dengan menjalani profesi sebagai Pekerja Seks Komersial dan terjebak dalam dunia prostitusi, padahal prostitusi ini dinilai sebagai bentuk kejahatan (Rosyadi, 2011).

Dari pendapat diatas, penulis berpendapat bahwa faktor paling utama dari permasalahan prostitusi adalah kurangnya pendidikan agama yang menyebabkan rendahnya norma dan moral pelaku. Generasi penerus bangsa harus menjunjung tinggi moral dan agama.

Kehadiran internet seolah memberi sebuah angin segar bagi para pelaku prostitusi dalam menjerat lelaki hidung belang. Embel embel online di belakang kata prostitusi semakin memudahkan mereka dalam kegiatan prostitusi. Beragam aplikasi dunia maya semakin mempermudah Pekerja Seks Komersial dalam melakukan ritual malamnya. Penyalahgunaan internet untuk kegiatan amoral ini semakin mengkhawatirkan. Prostitusi di Indonesia merupakan hal yang ilegal, artinya bertentangan dengan nilai dan moral masyarakat. Apabila hal ini dibiarkan berlarut-larut maka Indonesia bisa di cap sebagai sarang prostitusi. Jika prostitusi tidak diberantas, akan menjadi ajang bisnis yang terus berkembang. Hal itu akan menjadikan Indonesia dianggap sebagai negara yang memelihara kemaksiatan (Yanto, 2016).

Sebuah fakta baru ditemukan bahwa prostitusi menjadi sebuah mata pencaharian. Putaran uang dalam bisnis ini sangat menggiurkan. Prostitusi ini menyasar masyarakat

\section{JURNAL KEWARGANEGARAAN}


dari berbagai kalangan. Pada jaman sekarang, para PSK ini tidak hanya dari golongan miskin, tetapi berasal dari golongan menengah ke atas. Mereka bahkan seorang akademisi yang melek informasi dan teknologi. Dengan demikian jika dulu prostitusi itu identik dengan warung remang-remang tapi sekarang telah bermetamorposis ke hotel bintang lima.

Penulis dibuat takjub dengan fenomena prostitusi di kota Yogyakarta, bukan karena kemolekan parasnya tapi dari cara mereka menjajakan dirinya. Lewat aplikasi dunia maya tanpa merasa bersalah dan malu malu para PSK tersebut mencantumkan biodata berupa nama, tarif dan cara pembokingannya. Ada yang include dan juga exclude. Include berarti harga yang tertera sudah termasuk sewa hotel sehingga para lelaki pemesannya yang harus mendatangi hotel tempat PSK bersemayam. Berbeda dengan exclude, ini belum termasuk biaya sewa hotel. Cara ini mengharuskan pelanggan untuk cek in terlebih dahulu di hotel sekitaran Yogyakarta lalu mengirimkan foto kunci kamarnya. Hanya dalam hitungan menit PSK tersebut sudah tiba di tempat yang sudah disepakati.

\section{METODE PENELITIAN}

Penelitian ini menggunakan metode kualitatif. Metode penelitian kualitatif sering disebut dengan metode penelitian naturalistik (Nurgiansah \& Widyastuti, 2019). Dengan metode ini, permasalahan yang terjadi di lapangan akan mampu dikupas sedetaildetailnya. Adapun pengambilan data menggunakan observasi yakni dengan pengamatan langsung di lokasi penelitian yaitu di sekitaran marioboro yogyakarta. Selain obeservasi, dilakukan juga wawancara dengan salah satu oknum Pekerja Seks Komersial. Metode wawancara digunakan untuk mengetahui bagaimana modus terjadinya prostitusi (Rusniawati, Sunarto, \& Handoyo, 2015). The interview is a data collection with a path of question and answer that is conducted systematically and based on the purpose of investigation., maksudnya wawancara adalah pengumpulan data dengan jalur tanya jawab yang dilakukan secara sistematis dan berdasarkan tujuan penyelidikan (Nurgiansah, 2020).

\section{HASIL DAN PEMBAHASAN}

\section{Pergeseran Praktek Prostitusi di Era Sekarang}

Prostitusi dipandang negatif karena praktek prostitusi meresahkan masyarakat (Fadhlillah, Raharjo, \& Ishartono, 2015). Prostitusi bukanlah hal baru yang sering diperdebatkan, prostitusi online yang semakin marak di Indonesia khususnya di Kota Yogyakarta menunjukkan bahwa telah terjadi peningkatan fenomena sosial di tengah masyarakat. Ini terjadi seiring dengan kemajuan ilmu pengetahuan dan teknologi yang disalahgunakan. Terciduknya beberapa artis papan atas Indonesia beberapa waktu yang lalu telah menguak beragam fakta adanya selebritas yang terlibat dalam prostitusi online. Mereka menggunakan media sosial terutama whatsapp sebagai alat pemasarannya. Semua orang dari berbagai kalangan telah memiliki gadget yang dapat digunakan, mulai dari anak anak sampai orang dewasa dapat dengan mudah mengakses situs-situs tertentu (Nurgiansah, 2019). 
Dahulu, para PSK adalah masyarakat kelas bawah yang terdesak kebutuhan ekonomi, mereka menghalalkan cara ini untuk memenuhi kebutuhan hidupnya. Seiring bertambahnya waktu, pelaku PSK sekarang tidak lagi masyarakat menengah ke bawah akan tetapi sudah menyasar kalangan atas yang berpendidikan dengan tarif yang mahal. Menurut pendapat kriminolog Universitas Gajah Mada, Suprapto mengakui bahwa telah terjadi pergeseran sosial akibat faktor lingkungan. Siapapun orangnya bisa beranggapan bahwa menjadi PSK mampu memenuhi kebutuhan prestise atau gengsi yang membuatnya justru bangga ketimbang memanggul aib.

Pemicu lainnya adalah alasan aji mumpung atau terlanjur basah. Dari adanya kesempatan, orang yang tadinya enggan bisa tergoda dan iseng untuk sekedar coba-coba. Setelah mencoba, seringnya orang memasuki zona nyaman mendapatkan hasil yang instan yang pada akhirnya prostitusi kadung dianggap sebagai jalan pintas untuk menghasilkan pundi-pundi uang yang banyak.

Beberapa faktor yang menjadi penyebab terjadinya prostitusi melalui media online, yang pertama adalah lemahnya tingkat keimanan dan ketakwaan seseorang kepada Tuhan yang maha kuasa. Pada hakekatnya, keimanan dan ketakwaan merupakan sebuah landasan bagi seorang dalam rangka menjalani kehidupan yang fana ini. Semua agama mempunyai aturan dan batasan sendiri-sendiri mengenai perintah dan larangan-Nya. Tidak ada satu pun agama di dunia ini yang memperbolehkan dan membiarkan praktek prostitusi terjadi. Dengan dilandasi keimanan dan ketakwaan yang baik dan benar, diharapkan seseorang akan kuat menjalani kehidupan ini dan tidak tergoda dengan nafsu sesaat yang menjerumuskan kepada dosa dan kehinaan.

Faktor yang kedua adalah kemiskinan. Kemiskinan mampu untuk memaksa banyak orang menjual dirinya dan menanggalkan moralnya. Pada dasarnya yang menjadi penyebab utama terjadinya prostitusi adalah keterpurukan dan keterbatasan kondisi ekonomi seseorang. Faktor sosiologis adanya prostitusi adalah kemiskinan (Anindia \& Sularto, 2019). Penghasilan orang tua tidak mencukupi untuk menunjang kehidupan ekonomi keluarga (Lang, 2014). Begitu banyak orang yang kehilangan pekerjaan. Peluang kerja dan ketersediaan lapangan kerja yang ada tidak sebanding dengan jumlah orang yang mencari pekerjaan ditambah lagi dengan lulusan baru yang belum mempunyai keterampilan apapun. Keadaan ini praktis membuat orang berupaya keras mencari pekerjaan hingga ke negara lain menjadi seorang Tenaga Kerja Indonesia.

Faktor selanjutnya yang ketiga yaitu keinginan seseorang untuk cepat menjadi kaya raya secara cepat. Keinginan untuk memiliki semua materi yang dimiliki oleh orang lain dan standar hidup yang lebih tinggi agar mampu bersaing dan tetap menunjukkan eksistensinya. Semua aktivitas ini sudah mulai masuk di lingkungan pendidikan formal. Banyak pelajar SMP, SMA, dan Mahasiswa yang terjun dalam praktek prostitusi ini karena didorong oleh keinginan untuk dapat segera memenuhi kebutuhan gaya hidup yang mewah sehingga tidak kalah pamor dengan rekan seusianya.

Faktor keempat adalah lemahnya penegakan hukum oleh aparat penegak hukum dalam mengawasi dunia maya. Kegiatan prostitusi online merupakan bahaya bagi semua pihak dan selalu berkembang meskipun terus diberantas. Oleh karena itu, ketegasan dari aparat penegak hukum dalam memberikan sanksi pada pelaku prostitusi harus semakin digalakkan. Bahkan tak jarang terdapat ulah dari beberapa oknum aparat yang membekingi prostusi ini karena menerima kucuran dana pula. Kejujuran dan kegigihan aparat harus dibarengi pula dengan Undang-undang yang baik.

\section{JURNAL KEWARGANEGARAAN}


Kemudian faktor yang kelima adalah faktor budaya. Budaya cyberporn di internet dengan cara memasang foto-foto vulgar tanpa rasa malu dan secara terang-terangan menawarkan dirinya dengan tarif tertentu. Budaya malu masyarakat kita semakin hari semakin terkikis dikarenakan pengaruh budaya barat yang menganggap seks bukan hal yang tabu. Budaya ketimuran kita lambat laun akan hilang karena terus menerus disuguhi tontonan yang amoral. Situs prostitusi online dapat menjadikan sebuah wadah atau media bisnis yang mampu memberikan keuntungan besar jika dibandingkan dengan bentuk prostitusi biasa.

\section{Prostitusi Dilihat dari Segi Kemanusiaan}

Pancasila sila ke 2 telah memberikan amanat bahwa setiap warga negara menjunjung nilai kemanusiaan yang adil dan beradab dalam kehidupan berbangsa dan bernegara (Aditya, 2016). Nilai kemanusian dalam sila kedua pancasila berbunyi "kemanusiaan yang adil dan beradab" bermakna bahwa dalam konteks negara pancasila kemanusiaan berarti melindungi dan menjunjung tinggi harkat dan martabat manusia sesuai dengan kodratnya yang mempunyai akal, pikiran, perasaan dan keyakinan. 4 hal inilah yang membedakan manusia dengan mkhluk lainnya. Dengan adanya akal dan pikiran manusia mampu untuk bertahan hidup dan mempertahankan kehidupannya dari berbagai gangguan dan ancaman yang mengintai. Begitupun dengan perasaan dan keyakinan yang dimiliki manusia berfungsi sebagai pembeda mana yang baik dan mana yang buruk. Dengan demikian sudah selayaknya perilaku prostitusi dinilai jauh dari sifat harkat dan martabat manusia.

Salah satu cara paling manusiawi untuk memberantas prostitusi adalah dengan mendekatkan para PSK tersebut pada ilmu agama. Bagaimanapun juga negara kita selain mempunyai aturan negara punya aturan agama. Cara-cara penyelesaian yang tidak manusiawi seperti penggrebegan, penjemputan paksa sampai diliput media harus dihilangkan. Apalagi dengan menaikan para pelaku ke atas mobil truk polisi pamong praja dapat dianalogikan seperti segerombolan sapi yang hendak disembelih di hari raya.

Aditya (2019) berependapat bahwa Pancasila sila ke 2 telah memberikan amanat bahwa setiap warga negara menjunjung nilai kemanusiaan yang adil dan beradab dalam kehidupan berbangsa dan bernegara. Pancasila terutama sila kedua memang memandang prostitusi sebagai penyelewengan dari segi kemanusiaan, akan tetapi memperlakukan mereka pun harus sesuai dengan kaidah harkat dan martabat manusia.

\section{Prostitusi Dilihat dari Segi Keadilan}

Di dalam pasal 27 ayat (2) Undang-Undang Dasar Negara Republik Indonesia 1945 menyebutkan bahwa setiap warga negara berhak untuk mendapatkan pekerjaan dan penghidupan yang layak bagi kemanusiaan. Pekerjaan dan penghidupan yang layak merupakan hak semua warga negara tanpa terkecuali agar terwujudnya kehidupan yang makmur, sejahtera dan adil. Jika para pelaku prostitusi beranggapan bahwa menjadi PSK merupakan pekerjaan yang layak maka hal tersebut adalah sesuatu yang keliru. Pancasila memandang ketidaklayakannya karena jauh dari nilai-nilai keadilan. Tidak sedikit para pelanggan merupakan anak di bawah umur. Salah satu kutipan wawancara dengan salah satu PSK di Yogyakarta mengatakan bahwa kebanyakan pelanggannya adalah pelajar SMA yang menggunakan uang untuk keperluan sekolah dalam membayar tarif PSK. Hal ini tentu merusak generasi penerus bangsa. Orang tua di rumah dan guru di sekolah 
mengarahkan dan membimbing anak tersebut untuk belajar dan menjadi manusia yang berakhlak tetapi para pelaku prostitusi ini malah menjerumuskan pada sesuatu yang merugikan masa depannya. Kebanyakan para pelaku prostitusi adalah wanita, sehingga menimbulkan dampak kerugian yang lebih banyak dari pada pria. Hal ini jauh dari rasa keadilan karena adanya diskriminasi dari segi gender.

Perlakuan diskriminasi antara laki-laki dan wanita pelaku prostitusi sangat bertentangan dengan Undang-Undang Dasar Negara Republik Indonesia Tahun 1945. Dalam pasal 28D ayat 1 menyebutkan bahwa setiap orang berhak atas pengakuan, jaminan, perlindungan, dan kepastian hukum yang adil serta perlakuan yang sama di hadapan hukum. Perlakuan diskriminasi merupakan suatu pelanggaran HAM dan bertentangan dengan konsep HAM tentang persamaan dan keadilan yang dijunjung oleh HAM yang berhak dinikmati oleh setiap orang. Oleh karenanya, Diskriminasi merupakan perbuatan yang dilarang berdasarkan aturan hukum dan dimana ada tindakan diskriminasi maka terdapat pelanggaran hak asasi manusia disana. Oleh karenanya merupakan hak PSK untuk mendapat perlakuan yang sama tanpa diskriminasi dalam kehidupan bermasyarakat, berbangsa, dan bernegara serta dilindungi oleh hukum.

Setiap hari para pelaku prostitusi selalu mendapatkan perlakuan yang diskriminasi. Salah satu perlakuan diskriminasi tersebut adalah peraturan perundang-undangan yang berlaku melarang kegiatan prostitusi tanpa mencarikan solusinya. Seharusnya undangundang menjamin mata pencaharian yang layak bagi mereka agar terbebas dari belenggu prostitusi. Dengan tidak adanya payung hukum sebagai bentuk perlindungan terhadap wanita yang menjajakan dirinya maka pelaku prostitusi akan mendapatkan perlakuan sewenang-wenang. Pemerintah selayaknya memandang para wanita yang terlibat prostitusi sebagai korban dampak dari ketiadaannya lapangan kerja.

\section{Prostitusi Dilihat dari Sisi Keadaban.}

Bangsa yang beradab adalah bangsa yang menjalankan segala peraturan perundangundangan dengan baik dan benar. Keadaban suatu bangsa tergantung dari keadaban warga negaranya. Prostitusi merupakan kegiatan yang tidak beradab. Pelacuran disebut melanggar norma kesusilaan sebab perbuatan melacurkan diri dari para pelacur kepada banyak laki -laki, yakni mengelilingi kota sepanjang malam sambil mencari laki -laki untuk melampiaskan nafsu birahi (seksual) sambil mengharapkan imbalan uang atau jasa lainnya dan atau mengadakan relasi seks yang tidak beradab (menjual diri / kehormatannya) demi untuk memperoleh uang yang banyak. Nilai keadaban harus sejalan lurus dengan moralitas yang baik dan norma agama. Para pelaku prostitusi telah menghianati negara dengan tidak menerapkan dan menjalankan nilai-nilai yang terkandung dalam ideologi pancasila. Mereka jauh dari nilai keadaban, moral mereka rusak. Bangsa Indonesia menganut Asas Ketimuran, bukan kebarat-baratan, untuk mendukung hal ini diperlukan pendidikan berbasis karakter. Character education is a good solution to be implemented to form a strong character of the younger generation atau pendidikan karakter adalah solusi yang baik untuk diimplementasikan dalam membentuk karakter yang kuat dari generasi muda yang akan membawa masyarakat Indonesia semakin beradab (Nurgiansah, Dewantara, \& Rachman, 2020).

\section{JURNAL KEWARGANEGARAAN}




\section{SIMPULAN}

Dilihat dari sila kedua pancasila, nilai kemanusiaan menganggap prostitusi sebagai tindakan tak beradab, jauh dari harkat dan martabat manusia. Apapun alasan dari para pelaku dalam menjalankan aksinya tetap saja hal tersebut tidak bisa dibenarkan karena melanggar norma hukum dan juga norma agama. Selain diperlukannya penguatan nilainilai pancasila, ketegasan dari pemerintah dan aparat penegak hukum tidak bisa ditawar.

Para pelaku prostitusi dan juga pemakai jasanya harus ditindak tegas sesuai dengan peraturan perundang-undangan yang berlaku. Kemudian pemerintah tidak hanya menutup tempat lokalisasi tetapi perlu juga tindakan lanjutan seperti memonitor dan mengawasi PSK agar tidak berpindah tempat dalam menjalankan kegiatan prostitusinya karena penutupan lokalisasi bukan jaminan bahwa prostitusi akan hilang. Terakhir perlu adanya evaluasi dalam pemanfaatan dan penggunaan internet agar tidak terjadi penyalahgunaan. Semua pihak harus bekerja sama dalam mencegah kegiatan prostitusi ini, pemerintah, kepolisian, dan masyarakat harus berpangku tangan bahu membahu dalam penerapan nilai kemanusian yang adil dan beradab.

\section{UCAPAN TERIMA KASIH}

Penulis mengucapkan terima kasih kepada berbagai pihak yang turut terlibat dalam penelitian ini terutama tim cyber crime Polda DIY dan kepada LPPM Universitas PGRI Yogyakarta yang telah mendanai penelitian ini.

\section{DAFTAR PUSTAKA}

Aditya, L. E. (2016). Urgensi Kriminalisasi Terhadap Pelacuran dalam Pembaharuan Hukum Pidana di Indonesia. Universitas Brawijaya.

Anindia, I. A., \& Sularto, R. B. (2019). Kebijakan Hukum Pidana dalam Upaya Penanggulangan Prostitusi Sebagai Pembaharuan Hukum Pidana. Jurnal Pembangunan Hukum Indonesia, $\quad 1(1), \quad 18-30$. https://doi.org/10.14710/jphi.v1i1.18-30

Fadhlillah, D. F., Raharjo, S. T., \& Ishartono, I. (2015). Pemenuhan Hak Anak dalam Keluarga di Lingkungan Prostitusi. Prosiding Penelitian dan Pengabdian kepada Masyarakat, 2(1). https://doi.org/10.24198/jppm.v2i1.13262

Lang, L. C. M. (2014). Perlindungan Hukum Terhadap Hak Anak Korban Praktek Prostitusi Dari Wisatawan. Lex et Societatis, II(1), 105-113.

Marcius, S. M. S., \& Simatupang, T. (2018). Tinjauan Yuridis Terhadap Tindak Pidana Penyedia Sarana Praktik Prostitusi (Tinjauan Putusan No. 2156/PID.SUS/2016/PNMDN). Ilmu Hukum Prima (IHP), 2(1).

Nurgiansah, T. H. (2019). Penyusunan Kurikulum Pendidikan Tinggi Di Era Revolusi Industri 4.0. Prosiding Seminar Kewarganegaraan Universitas Negeri Medan, 95102. 
Nurgiansah, T. H. (2020). Build an Attitude of Nationalsm Students at SDN 7 Kadipaten with the Method of Discussion in the Subject PPKn. Jurnal Serunai Pancasila dan Kewarganegaraan, 9(1), 1-11. https://doi.org/10.37755/JSPK.V9I1.243

Nurgiansah, T. H., Dewantara, A., \& Rachman, F. (2020). The Implementation of Character Education in the Civics Education Syllabus at SMA Negeri 1 Sleman. JED (Journal of Etika Demokrasi), 5(2), 110-121. https://doi.org/10.26618/JED.V5I2.3106

Nurgiansah, T. H., \& Widyastuti, T. M. (2019). Membangun Kesadaran Hukum Mahasiswa PPKn UPY dalam Berlalu Lintas. Civic Edu: Jurnal Pendidikan Kewarganegaraan, 2(2), 97-102. https://doi.org/10.23969/CIVICEDU.V2I2.1491

Prayoga SM, M. R. (2019). Kebijakan Hukum Pidana Dalam Penanganan Praktik Prostitusi Di Kalangangenerasi Muda (Studi pada Kepolisian Daerah Sumatera Utara). Fakultas Hukum Universitas Muhammadiyah Sumatera Utara.

Rosyadi, A. (2011). Kajian Yuridis Terhadap Prostitusi Online Ahmad Rosyadi. Fakultas Syariah dan Hukum Universitas Islam Negeri Syarif Hidayatullah Jakarta.

Rusniawati, I., Sunarto, \& Handoyo, E. (2015). Prostitusi di Kalangan Pedagang di Jalan Pantura Alas Roban Kabupaten Batang. Unnes Civic Education Journal, 1(2).

Yanto, O. (2016). Prostitusi Online Sebagai Kejahatan Kemanusiaan terhadap Anak: Telaah Hukum Islam dan Hukum Positif. AHKAM : Jurnal Ilmu Syariah, 16(2), 187-196. https://doi.org/10.15408/ajis.v16i2.4449 